\title{
Thoracoscopic complex basilar segmentectomies: an analysis of 63 procedures
}

\author{
Dominique Gossot ${ }^{1} \wedge$, Alessio Vincenzo Mariolo ${ }^{1}$, Madalina Grigoroiu ${ }^{1}$, Jérémy Bardet ${ }^{1}$, Guillaume Boddaert ${ }^{1}$, \\ Emmanuel Brian ${ }^{1}$, Agathe Seguin-Givelet ${ }^{1,2}$ \\ ${ }^{1}$ Thoracic Department, Curie-Montsouris Thorax Institute-Institut Mutualiste Montsouris (IMM), Paris, France; ${ }^{2}$ Paris 13 University, Sorbonne \\ Paris Cité, Faculty of Medicine SMBH, Bobigny, France \\ Contributions: (I) Conception and design: D Gossot, AV Mariolo, A Seguin-Givelet; (II) Administrative support: D Gossot, A Seguin-Givelet; (III) \\ Provision of study materials or patients: D Gossot, A Seguin-Givelet, M Grigoroiu, E Brian, A Vincenzo Mariolo; (IV) Collection and assembly of \\ data: AV Mariolo, A Seguin-Givelet; (V) Data analysis and interpretation: D Gossot, AV Mariolo, A Seguin-Givelet; (VI) Manuscript writing: All \\ authors; (VII) Final approval of manuscript: All authors. \\ Correspondence to: Dominique Gossot. Thoracic Department, IMM, 42 Bd Jourdan, F-75014 Paris, France. Email: dominique.gossot@imm.fr.
}

Background: Thoracoscopic complex basilar segmentectomies are technically demanding and challenging. We review our experience to check whether this complexity can lead to specific surgical issues or increased post-operative morbidity.

Methods: Complex basilar segmentectomies were defined as the anatomical resection of at least one segment composing the basilar pyramid, excluding $\mathrm{S}^{6}$. Data of patients who had an intention-to-treat thoracoscopic complex basilar segmentectomy were retrospectively collected from 2007 to 2019: indications, preoperative assessment, clinical features, operative technical aspects and early post-operative outcome.

Results: Sixty-three patients, 26 men (41\%) and 37 women (59\%) with a median age of 66 years and a median body mass index (BMI) of $26 \mathrm{~kg} / \mathrm{m} 2$ were included. Interventions performed were mostly S ${ }^{9+10}(\mathrm{n}=32)$ and $S^{8}(n=12)$ segmentectomies. Forty-five planned operations (71\%) were completed. Extension to a larger resection was necessary in 17 patients $(27 \%)$ and 4 patients underwent conversion to open surgery $(6 \%)$. Median operative time was 168 minutes with a median intraoperative bleeding of $30 \mathrm{~mL}$. Complications occurred in 11 patients (17\%). There was no mortality. Median length of pleural drainage was 2 days (range, 1-2 days) and median hospital stay 4 days.

Conclusions: The extension rate of complex basilar segmentectomy is higher than that of other sublobar resections but their post-operative morbidity is identical.

Keywords: Thoracoscopy; sublobar resection (SLR); segmentectomy; basilar segmentectomy; complex segmentectomy

Submitted Dec 15, 2020. Accepted for publication Apr 09, 2021.

doi: $10.21037 /$ jtd-20-3521

View this article at: https://dx.doi.org/10.21037/jtd-20-3521

\section{Introduction}

Interest in sublobar resections (SLRs) for early-stage nonsmall cell lung cancer (NSCLC) is increasing and their indications are gradually expanding (1). The objective of SLRs is to spare respiratory function while expecting to perform a resection respecting the same oncological principles than a lobectomy. The functional benefit of SLR is optimal when the number of resected segments is limited (2). Thus, when the surgeon needs to remove a benign lesion, a solitary metastasis or a pure ground glass

^ ORCID: 0000-0002-7038-1924. 
opacity (GGO) localized in the lower lobe, it might be more beneficial to spare the maximum of lung parenchyma possible thus performing a limited resection of one or two segments than directly performing a basilar segmentectomy. Nevertheless, the partial resection of the basilar segments is a complex and challenging procedure, especially when performed thoracoscopically $(3,4)$. Reasons are multiple and include high anatomical variability, difficult intersegmental plane (ISP) delineation and three-dimensional (3D) stapling of the ISP caused by the pyramidal shape of the lower lobe $(3,5)$. For these reasons, complex basilar segmentectomy (CBS) are often precluded due to the perceived augmented risk of failure and for augmented potential post-operative complications. The aim of this study was to verify if the technical difficulties related to this complexity resulted in a high rate of extension to a larger resection, or conversion to thoracotomy, or early post-operative morbidity. Long-term outcome and survival are not part of this work and have been analyzed in another study (6).

We present the following article in accordance with the STROBE reporting checklist (available at https://dx.doi. org/10.21037/jtd-20-3521).

\section{Methods}

A single-center retrospective analysis was performed in our center from January 2007 to December 2019 for patients with an intention-to-treat thoracoscopic CBS. Intraoperative and postoperative data were prospectively recorded in a database that was approved from our Institutional Review Board (CEPAR 2013-002). The study was conducted in accordance with the Declaration of Helsinki (as revised in 2013). The study was approved by the Ethical Committee for Clinical Research of the French Society for Thoracic and Cardiovascular Surgery (CERCSFCTCV-2020-07-03---13-SEAG) and individual consent for this retrospective analysis was waived. In this article, we considered as CBS every partial anatomical resection of the lower lobe excluding $\mathrm{S}^{6}$. It is assumed that segmentectomy means "anatomical segmentectomy" with individual control of the broncho-vascular pedicle and intersegmental lymph node resection. Data collected included the type of segmentectomy planned, clinical features [gender, age and body mass index (BMI)], intraoperative characteristics (length of surgery and intraoperative bleeding) and postoperative characteristics (final pathology, length of pleural drainage, length of hospital stay). Thirty-day post-operative complication was assessed following the Clavien-Dindo classification (7). Reasons for extension and conversion were analyzed. Thirty- and 90-day mortality was included. We defined "extension" as a larger resection than expected, including adjacent segment, the entire basilar segments, i.e., $\mathrm{S}^{7-10}$ or $\mathrm{S}^{8-10}$ ) — or the whole inferior lobe. Indication for CBS was posed: (I) in patients with highly suspected or proven metastases that was unresectable by mere wedge resection; (II) in patients with highly suspicious and evolutive GGO; (III) in patients with proven or suspected cT1aN0 NSCLC considered to be poor candidates for lobectomy because of impaired cardiopulmonary function or major comorbidities; (IV) in patients with a previous lobectomy for NSCLC presenting with synchronous early-stage lesions.

For patients operated on for NSCLC, postoperative staging was assessed using the $8^{\text {th }}$ edition of the tumor, nodes and metastasis (TNM) classification.

\section{Technique}

For all patients, a full thoracoscopic fissure-based multiple ports approach was used as previously described $(8,9)$. Briefly, an extensive dissection of the pulmonary artery branches in the fissure is performed, followed by a tunneling technique to separate $\mathrm{S}^{6}$ from $\mathrm{S}^{10}$, to facilitate the exposure and resection of the arterial branches (10). The proper bronchus-or bronchi-are carefully dissected to avoid any tear of the veins that usually run behind them and are stapled after a reventilation test. In the rare patients with classical venous anatomy, i.e., inferior basilar vein, superior basilar vein and $\mathrm{V}^{6}$, the segmental veins could be controlled at the hilum level. Otherwise, especially when the venous anatomy makes this dissection hazardous, they are controlled within the parenchyma once the bronchus and artery have been divided (Figure 1). Before ISP division, hilar structures are released to allow an easier exposure of the stumps to be resected in particular concerning the intersegmental bronchus and vein.

In our preliminary experience, ISP was determined using a conventional insufflation-deflation method. We then attempted intrabronchial injection of methylene blue in the whole segment to be resected via electromagnetic navigation bronchoscopy (ENB). Since November 2017, these two methods were abandoned and we switched to near-infrared imaging (IRI) with systemic injection of indocyanine green (ICG) (Figure 2).

In case of malignancy, all peri-bronchial (station 11), interlobar and intersegmental (stations 12 and 13) lymph nodes are cleared (Figure 3A). In case of patients operated 

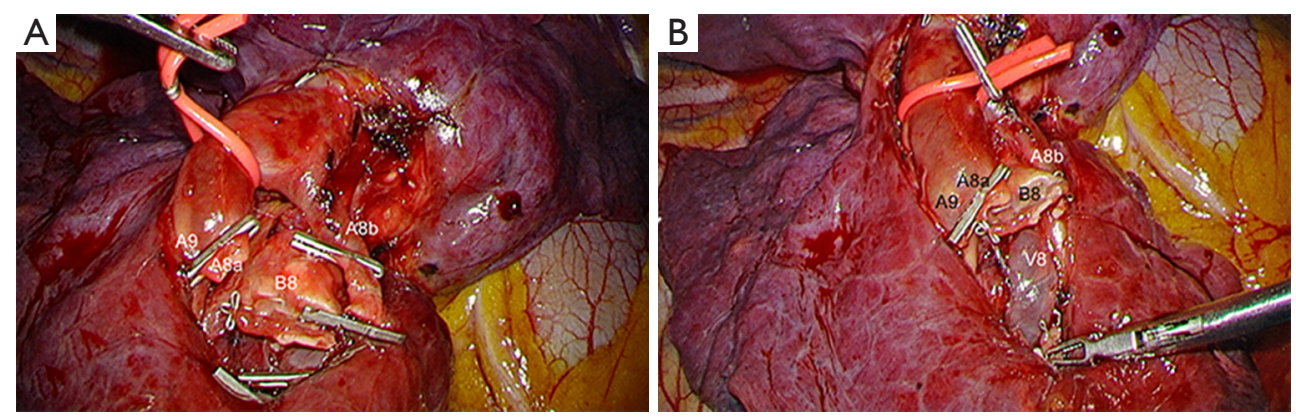

Figure 1 Control of the segmental vein. (A) Exposure of $A^{8} a, A^{8} b$ and $B^{8}$ resected during a thoracoscopic $S^{8}$ segmentectomy; (B) exposure of the underlying $\mathrm{V}^{8}$ after the resection of the bronchus.

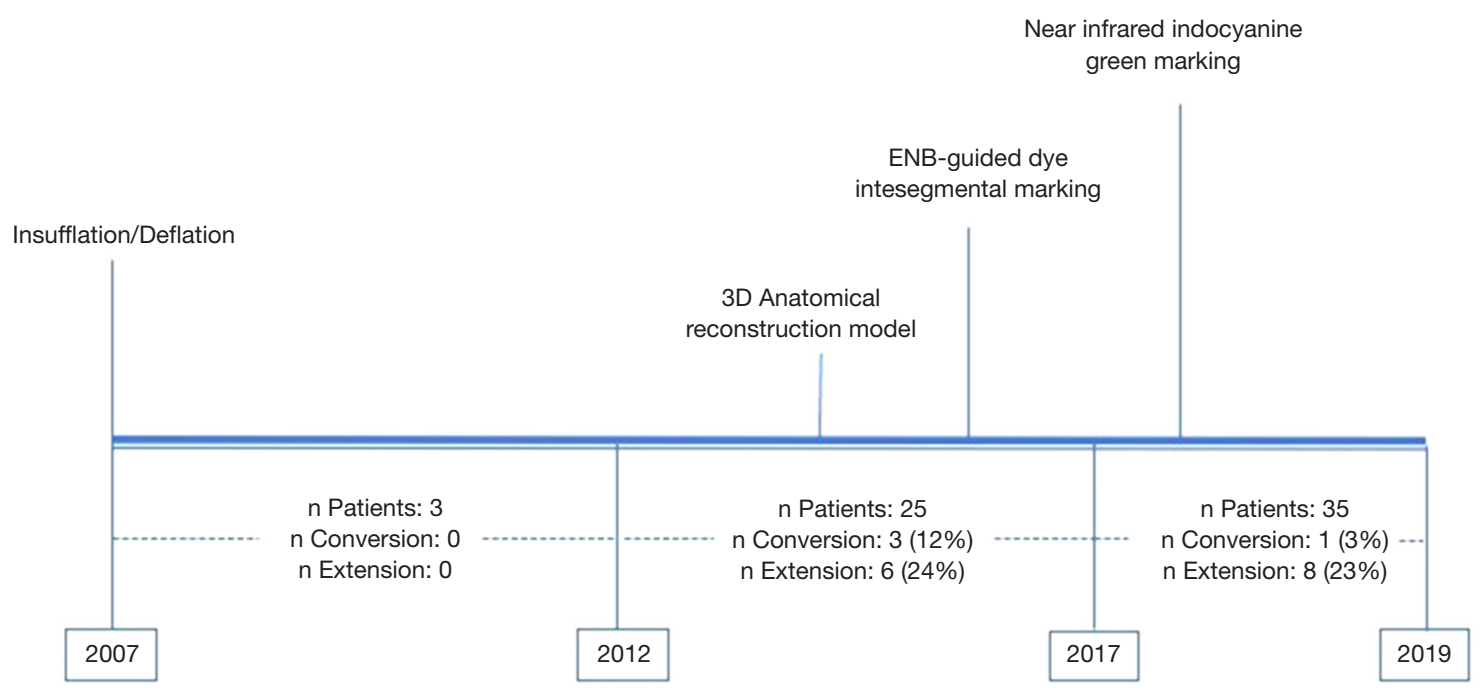

Figure 2 Timeline showing the distribution of patients and technological adoptions during the analyzed period of the study.

for malignancies, intersegmental lymph nodes and safety margins (Figure 3B) are always examined by frozen section. The procedure is transformed into a basilar segmentectomy if insufficient safety margins or into lobectomy in case of invaded intersegmental lymph nodes. In patients with primary NSCLC, the segmentectomy is completed by a radical hilar and mediastinal lymph node dissection.

\section{Results}

From September 2007 to November 2019, 646 full thoracoscopic SLR have been performed in our department. Of these, 63 full thoracoscopic anatomical intention-totreat CBSs were included. Fifty-four segmentectomies were intentional with indication to treat early-stage small size (i.e., T1aN0) lesions $(n=20,32 \%)$ or pure GGO $(n=4$,
$6 \%)$, proven or highly suspected typical carcinoid tumor $(\mathrm{n}=6,10 \%)$, proven or highly suspected metastatic lesion otherwise unresectable via wedge resection $(n=20,31 \%)$ proven benign pathology $(n=4,6 \%)$. Nine segmentectomies were unintentional due to second synchronous or metachronous lung cancer $(n=4,6 \%)$, or proposed to patients with impaired cardiopulmonary function or major comorbidities $(\mathrm{n}=5,8 \%)$. Data are presented as absolute numbers or in median (lower and upper quartiles). There were 26 men (41\%) and 37 women (59\%) with a median age of 66 years (57-71 years), a median BMI of $26 \mathrm{~kg} / \mathrm{m}^{2}$ $\left(22-29 \mathrm{~kg} / \mathrm{m}^{2}\right)$ and a median forced expiratory volume in the first second (FEV1) of 90\% (75-102\%) and a diffusing capacity of lung for carbon monoxide (DLCO) of $75 \%$ (65-82\%). The types of planned CBS are summarized in Table 1. Forty-five procedures (71\%) were completed. 
Table 1 Planned operation and finally procedures performed

\begin{tabular}{|c|c|c|c|c|c|c|c|c|}
\hline \multirow{2}{*}{$\begin{array}{l}\text { Type of planned basal } \\
\text { segmentectomy ( } n \text { ) }\end{array}$} & \multicolumn{2}{|c|}{ Total } & \multirow{2}{*}{ Right } & \multirow{2}{*}{ Left } & \multirow{2}{*}{ Accomplished } & \multirow{2}{*}{ Extension } & \multirow{2}{*}{ Conversion } & \multirow{2}{*}{$\begin{array}{l}\text { Conversion and } \\
\text { Extension }\end{array}$} \\
\hline & $\mathrm{N}$ & $\%$ & & & & & & \\
\hline$S^{9+10}$ & 32 & 51 & 15 & 17 & 22 & $\begin{array}{c}\text { 8: } 5 \text { lower lobectomies; } \\
3 \text { basal segmentectomies }\end{array}$ & 0 & $\begin{array}{l}2: 1 \text { lower lobectomy; } \\
1 \text { basal segmentectomy }\end{array}$ \\
\hline$S^{8}$ & 12 & 19 & 4 & 8 & 9 & 2 basal segmentectomies & 1 & 0 \\
\hline$S^{7+8}$ & 6 & 10 & 6 & 0 & 4 & 2 basal segmentectomies & 0 & 0 \\
\hline$S^{10}$ & 5 & 8 & 2 & 3 & 3 & $1 S^{9+10}$ & 0 & 1 basal segmentectomy \\
\hline $\mathrm{S}^{8+9}$ & 2 & 3 & 0 & 2 & 1 & 1 basal segmentectomy & 0 & 0 \\
\hline$S^{7+10}$ & 1 & 2 & 1 & 0 & 1 & 0 & 0 & 0 \\
\hline
\end{tabular}
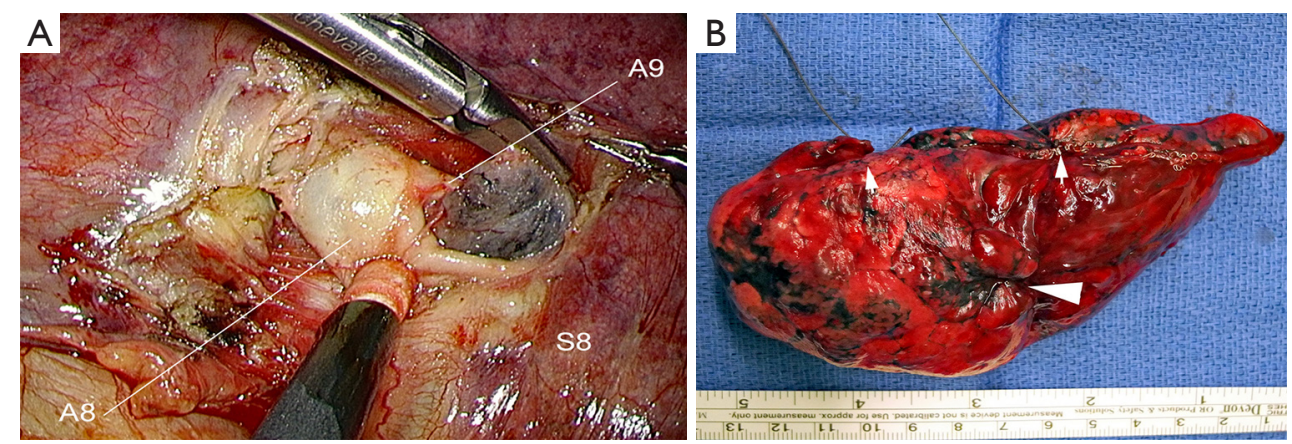

Figure 3 Intraoperative examination of segmental lymph nodes and margins. (A) Intersegmental lymph nodes dissected and removed for frozen section, during a left $\mathrm{S}^{9+10}$ segmentectomy; (B) intraoperative examination of safety margins during a left $\mathrm{S}^{10}$ segmentectomy. Large arrow = tumor; small arrows = marking of the portion of the staple line to be examined.

Extension to a larger resection was necessary in 17 patients $(27 \%)$. In particular, to a basilar segmentectomy $\left(\mathrm{S}^{7-10}\right.$ on the right side or $S^{8-10}$ on the left side) in 10 patients, to an adjacent segment $\left(\mathrm{S}^{10}\right.$ to $\left.\mathrm{S}^{9+10}\right)$ in 1 patient and to a lower lobectomy in 6 patients. Conversion to thoracotomy was required in 4 patients $(6 \%)$. The reasons for extension and conversion are reported in Table 2 and include hemorrhage, positive or doubtful intersegmental margins at frozen section and technical difficulties during bronchial dissection or dividing the ISP. Final pathological diagnoses and pathological staging are reported in Table 3. In 5 patients (8\%) the targeted lesion was not found in the final specimen thus requiring extension to a larger resection and in 3 cases the lesion was finally located following extension. In one patient operated for a $11 \mathrm{~mm}$ lesion with a pancreatic metastatic disease under chemotherapy, no lesion was found at final pathology. Post-operative follow-up with serial computed tomography (CT)-scan didn't detect suspicious lesion or recurrence. In a second patient, a $S^{8}$ segmentectomy was performed with no lesion at final pathological examination. A post-operative bronchoscopy showed that the lesiona typical carcinoid tumor-was still in place. Due to postoperative complications, in particular a bilateral pulmonary embolism, this elderly patient was not re-operated and he is currently under surveillance without disease progression. From July 2015 3D CT reconstruction and modelization was used (5). Median length of surgery was 168 minutes (133-213 minutes) with a median intraoperative blood loss of $30 \mathrm{~mL}(35-150 \mathrm{~mL})$. Median length of pleural drainage was 2 days (1-2 days) and a median hospital stay was 4 days (3-5 days). Post-operative complications occurred in 11 patients (17\%): 4 prolonged air leak (6\%, Clavien-Dindo I), 2 atrial fibrillation (3\%, Clavien-Dindo II), 1 unilateral pneumonia (2\%, Clavien-Dindo II) and 2 pulmonary 
Table 2 Reasons for extension and conversion and post-operative complications

\begin{tabular}{|c|c|c|}
\hline Variables & $\mathrm{N}[\%]$ & $\begin{array}{l}\text { Clavien-Dindo } \\
\text { classification }\end{array}$ \\
\hline \multicolumn{3}{|l|}{ Reasons of extension } \\
\hline Hemorrhage & 2 [3] & - \\
\hline Positive intersegmental margins & $3[5]$ & - \\
\hline $\begin{array}{l}\text { Technical difficulties in } \\
\text { intersegmental stapling }\end{array}$ & $3[5]$ & - \\
\hline Segmental bronchial tear & $1[2]$ & - \\
\hline Target nodule not found & $5[8]$ & - \\
\hline Total & 14 [22] & - \\
\hline Reasons of conversion & & - \\
\hline Hemorrhage & $3[5]$ & - \\
\hline $\begin{array}{l}\text { Technical difficulties in } \\
\text { intersegmental stapling }\end{array}$ & 1 [2] & - \\
\hline Total & $4[6]$ & - \\
\hline \multicolumn{3}{|l|}{ Post-operative complications } \\
\hline Prolonged air leak & $4[6]$ & I \\
\hline Pneumonia & $1[2]$ & II \\
\hline Atrial fibrillation & 2 [3] & II \\
\hline Pulmonary Embolism & 2 [3] & II \\
\hline Contralateral pneumothorax & $1[2]$ & IIIA \\
\hline Gastric perforation & $1[2]$ & IVA \\
\hline Total & $11[17]$ & \\
\hline
\end{tabular}

embolisms (3\%, Clavien-Dindo II). In one patient (2\%) a contralateral pneumothorax occurred in the immediate post-operative time requiring a pleural drainage insertion (Clavien-Dino IIIa) while one other patient (2\%) had an iatrogenic diaphragmatic puncture from trocar insertion, resulting in a gastric perforation requiring surgical reparation followed by peritonitis, leading to a prolonged hospital stay of 63 days (Clavien-Dindo IVa). There was no 30- or 90-day mortality attested. Intraoperative characteristics and postoperative complications are resumed in Table 4.

\section{Discussion}

At first sight, the benefit of performing a partial anatomical segmentectomy of the basal pyramid may seem unclear. However, indications are many and various: some benign
Table 3 Post-operative pathology and TNM staging for lung cancer

\begin{tabular}{|c|c|}
\hline Variables & $N[\%](n=63)$ \\
\hline \multicolumn{2}{|l|}{ Pathology } \\
\hline Primary malignancy & 33 [52] \\
\hline Adenocarcinoma & 22 [35] \\
\hline Squamous cell carcinoma & $3[5]$ \\
\hline Carcinoid tumor & $7[11]$ \\
\hline Localized SCLC & $1[2]$ \\
\hline Metastatic lesions & 20 [32] \\
\hline Bowel and colon cancer & $12[19]$ \\
\hline Renal cancer & $4[6]$ \\
\hline Breast cancer & $1[2]$ \\
\hline Hepatocellular carcinoma & $1[2]$ \\
\hline Endometrial carcinoma & $2[3]$ \\
\hline Benign lesions & 9 [14] \\
\hline Hamartochondroma & $3[5]$ \\
\hline Pulmonary sequestration & $3[5]$ \\
\hline Aspergilloma & $2[3]$ \\
\hline Bronchogenic cyst & $1[2]$ \\
\hline Unknown & $1[2]$ \\
\hline \multicolumn{2}{|c|}{ TNM staging for primary lung cancer } \\
\hline pT1a & $12[36]$ \\
\hline pT1b & $13[39]$ \\
\hline pT1c & $3[9]$ \\
\hline рT2a* & 4 [12] \\
\hline урт0** & $1[3]$ \\
\hline
\end{tabular}

conditions such as sequestrations or solitary metastases whose size and deep localization make them inaccessible to a wedge resection, typical carcinoid tumors, pure ground glass opacities and some stage I NSCLC. Handa et al. have recently shown that survival after complex SLR is similar to lobectomies for stage Ia NSCLC (11). In these various indications, the benefit of resecting 1 or 2 segments rather than the lower lobe or the basal pyramid allows for an optimal preservation of the respiratory function. According to Nomori et al, the whole lung function is significantly spared after segmentectomy compared to lobectomy 
Table 4 Time of surgery, length of pleural drainage, intraoperative blood loss, length of hospital stay

\begin{tabular}{|c|c|c|}
\hline Variables & Median & $25^{\text {th }}-75^{\text {th }}$ quartiles \\
\hline \multicolumn{3}{|l|}{ Duration of surgery (minutes) } \\
\hline Total & 168 & $133-213$ \\
\hline $\begin{array}{l}\text { Planned thoracoscopic CBS } \\
\text { completed }\end{array}$ & 165 & $130-215$ \\
\hline Thoracoscopic extension & 174 & 156-208 \\
\hline Conversion to open surgery & 220 & $202-303$ \\
\hline \multicolumn{3}{|l|}{ Intraoperative bleeding $(\mathrm{mL})$} \\
\hline Total & 30 & $35-150$ \\
\hline $\begin{array}{l}\text { Planned thoracoscopic CBS } \\
\text { completed }\end{array}$ & 50 & $20-150$ \\
\hline Thoracoscopic extension & 50 & $42-130$ \\
\hline Conversion to open surgery & 500 & $150-650$ \\
\hline \multicolumn{3}{|l|}{ Duration of chest drainage (days) } \\
\hline Total & 2 & $1-2$ \\
\hline $\begin{array}{l}\text { Planned thoracoscopic CBS } \\
\text { completed }\end{array}$ & 2 & $1-2$ \\
\hline Thoracoscopic extension & 2 & $1-2$ \\
\hline Conversion to open surgery & 3 & $2-4$ \\
\hline \multicolumn{3}{|c|}{ Duration of postoperative stay (days) } \\
\hline Total & 4 & $3-5$ \\
\hline Planned thoracoscopic CBS & 4 & $3-5$ \\
\hline Thoracoscopic extension & 4 & $3-5$ \\
\hline Conversion to open surgery & 5 & $4-33$ \\
\hline
\end{tabular}

CBS, complex basilar segmentectomy.

$(\mathrm{P}<0.001)$ (12). Segmentectomy spares the function of the operated lobe with $48 \% \pm 21 \%$ of the preoperative function, not only because of the preservation of the parenchyma but also because it increases the function of the ipsilateral nonoperated lobe. The result is optimal when the resection is limited, i.e., when only 1 or 2 segments are removed (2). The surgical complexity of the partial resections of the basal pyramid is mostly related to the numerous anatomical variations of the bronchovascular pedicle and to the pyramidal shape of the lower lobe that makes the ISP division difficult. Indeed, according to Sato et al. these SLR are the most complex to be performed (3).

\section{Anatomical difficulties}

From July 2015, a 3D modelization was performed to detect any anatomical variation and plan the optimal surgical strategy (Figure 4). During a thoracoscopic procedure, whatever the quality of vascular dissection, there is no way to apprehend the distal distribution of the segmental vessels. For example, we know that, on both sides, the distribution into a common trunk $\mathrm{A}^{9+10}$ with a separate $A^{8}$ artery is only valid in $90 \%$ of the cases (4). In $10 \%$ of patients, the distribution of arteries is different, with a common trunk $\mathrm{A}^{8+9}$ and a separate $\mathrm{A}^{10}$ artery, or even 4 independent arteries (13). Without a modelization, knowing which patient exhibits this anatomical variation is unpredictable. Furthermore, on the right side, the $\mathrm{A}^{7}$ artery may be missing in about $15 \%$ of patients. An additional sub-segment, known as $\mathrm{S}^{*}$, located between segments 6 and 10 , is present in $6 \%$ of cases and may cause identification concerns (4). Venous drainage may also vary. The typical distribution of the inferior pulmonary vein (IPV) into 3 main drainage branches is actually rare (14\% of cases) (4). More often a $\mathrm{V}^{6}$ vein and a common basal trunk are found or, on the contrary, an IPV receiving multiple segmental branches which are impossible to discriminate. For these several reasons, it seems almost impractical to embark on a partial basal segmentectomy without a 3D lung anatomical reconstruction. The software we are using (Visible Patient ${ }^{\mathrm{TM}}$, Strasbourg, France) allows investigating the anatomical landmarks, but also provides the useful functions such as simulation of the resection, volumetry of the segments and virtual identification of safety margins. Results and benefits of preoperative modelization have been widely reported $(5,13)$ and it has been shown that concordance between radiological images and intraoperative findings is superior to $95 \%$ (14). Three-D printing, if available, is also an option $(15,16)$.

\section{Separating segments 9 and 10 from segment 6}

One of the main concerns with CBS is to identify and to respect the veins draining segments 9 and 10 without injuring the $\mathrm{V}^{6}$ vein. One way to do this is to create a tunnel following the direction of the $\mathrm{V}^{6}$ vein (10). In this technique, the $\mathrm{V}^{6}$ vein is approached posteriorly, at the hilum level, and then in the fissure, creating a tunnel in the avascular zone. The plane between segment 6 and segments 9 and 10 is then stapled, thus exposing the entire basal vascularization (Figure 5). We now use this technique on a routine basis, but 

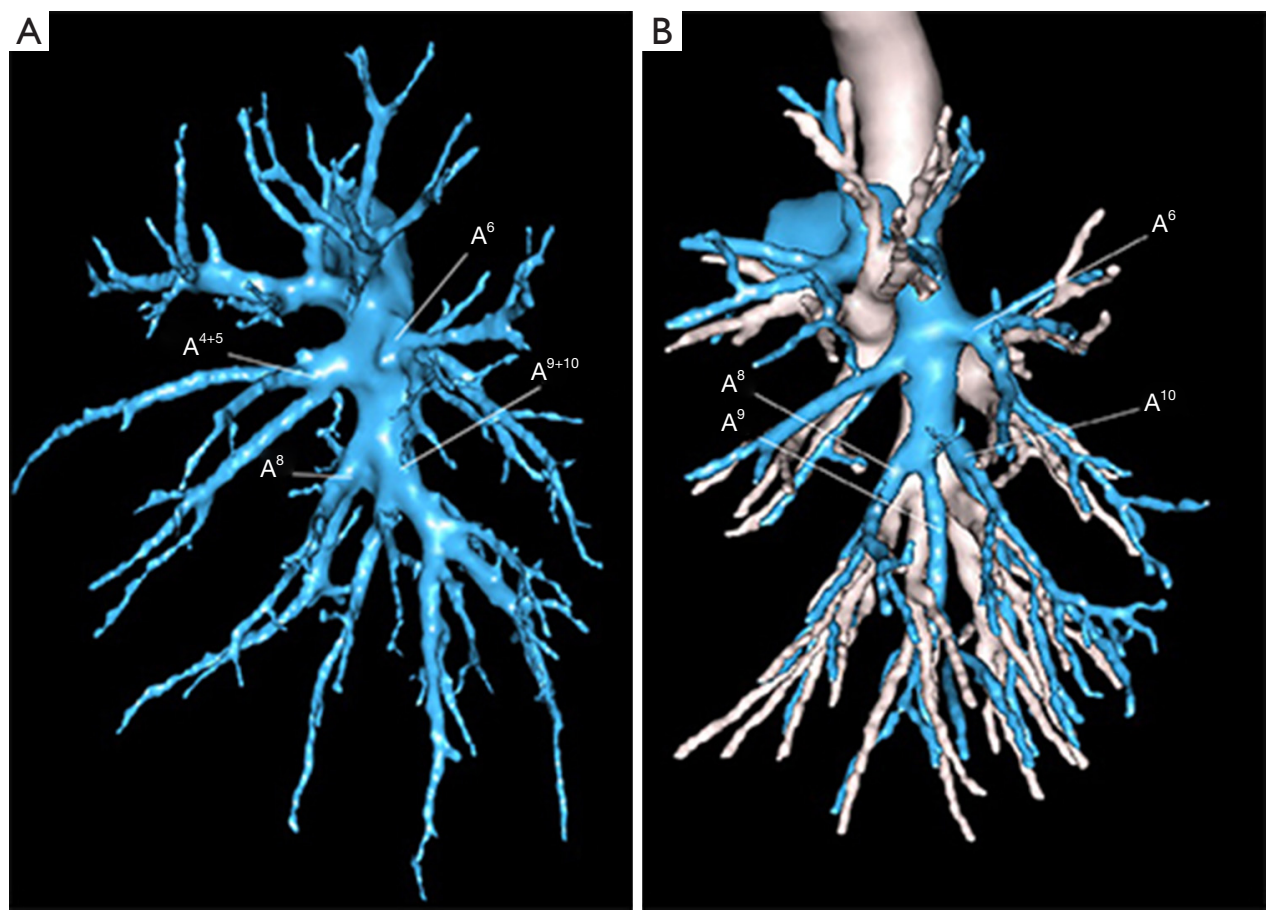

Figure $43 \mathrm{D}$ modelization of the arteries to the left basilar segments. (A) Usual pattern with a common arterial trunk $\mathrm{A}^{9+10}$ and separate $\mathrm{A}^{8}$; (B) less usual pattern with a common arterial trunk $\mathrm{A}^{8+9}$ and separate $\mathrm{A}^{9}$.

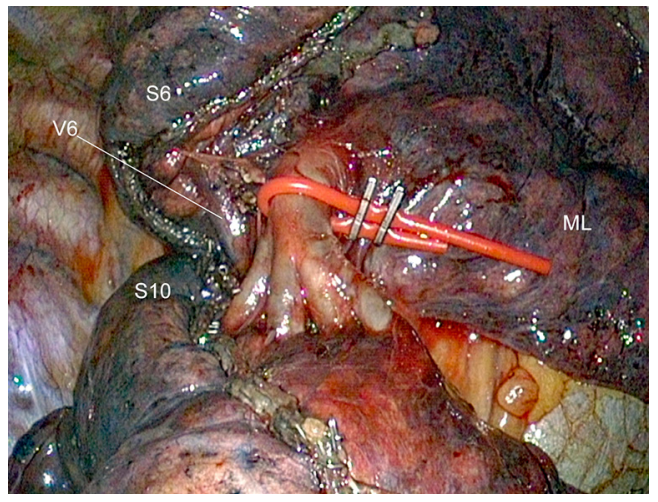

Figure 5 Exposure of basilar arteries after division of the plan between segment 6 and segments 9 and 10 .

its realization is sometimes tricky, especially when the lower lobe is difficult to mobilize. Other authors have proposed a purely posterior access $(3,17)$, retracting the $\mathrm{V}^{6}$ vein and approaching the bronchus and the $\mathrm{A}^{9}$ and/or $\mathrm{A}^{10}$ arteries from behind. As pointed out by Endoh et al., this approach has however the disadvantage of precluding dissection of the intersegmental lymph nodes (17).

\section{Management of the ISP}

Intersegmental plan represents one of the most delicate issues of CBS. Unlike linear or V-shaped ISP, described by Sato et al. (18), the pyramidal shape of the lower lobe requires a $3 \mathrm{D}$ stapling. The collapse of the pulmonary parenchyma by split ventilation can lead to spatial disorientation and makes stapling even more difficult. Sato et al. have developed a technique named virtual-assisted lung mapping (VAL-MAP) by virtual bronchoscopy (18). The technique makes it possible to mark both the target lesion and the ISP demarcation lines by instilling indigo carmine under fluoroscopic control. Initially we used a similar technique, injecting methylene blue under ENB guidance in the whole segment to be resected or as "spots" on the ISP plane defined by the IS vein, to identify the nodule and the boundaries of the adjacent segments (5). In the long run, this technique resulted tedious and, above all, not very accurate. We replaced it with a systemic ICG marking under IRI, after division of both arteries and veins of the segment to be resected (Figure 6). It permits precise identification of the ISP in all directions and facilitates stapling (15). Once the plane is marked, a step-by-step 


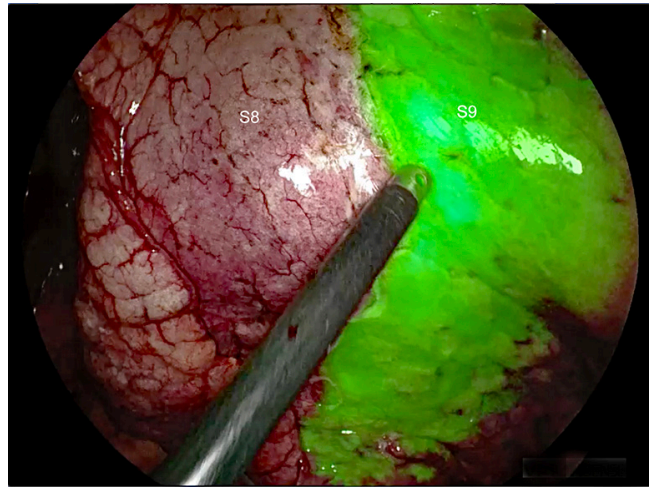

Figure 6 Delineation of the intersegmental plane by near-infrared imaging during a left $\mathrm{S}^{9+10}$ segmentectomy.

progression of stapling using small size reloads is advisable. That is safer and more precise than a direct stapling seeking to load the maximum amount of parenchyma with $60-\mathrm{mm}$ cartridges.

\section{Intersegmental lymph nodes analysis}

The analysis of intersegmental lymph nodes during SLR is crucial. We have previously shown that intraoperative examination of these lymph nodes may lead to a surgical extension of the planned resection (19). Failure to examine these lymph nodes exposes the patient to the risk of recurrence and may explain the poorer results of some SLR series. In addition, some patients who had no intersegmental lymph node clearance can be understaged and do not benefit from an adjuvant treatment. Whitson et al. and, more recently, Fang et al. have shown that the survival after SLRs is equivalent to that after lobectomies when lymphadenectomy is accurately performed $(20,21)$. Huang et al. have demonstrated that the number of harvested lymph nodes $\geq 6$ is independently associated with improved recurrence free survival for NSCLC patients undergoing segmentectomy (22).

\section{Safety margins analysis}

In this series of CBS, an extended resection was needed in 3 patients because of positive or highly suspicious intersegmental margins at frozen section. Compared to lobectomies, CBS may have an increased risk of local recurrence compared to a basal segmentectomy oreven more-to a lower lobectomy, if resection margins are inadequately close to the lesion. Schuchert et al. demonstrated that for patients with a stage I NSCLC, the results of SLR were comparable to lobectomy, but recurrence was more frequent in patients with a margin/ tumor ratio lower than 1 (23). The distance between the lesion and the staple line of the ISP is therefore decisive. Safety margins can be anticipated by preoperative modelization (24). On our 3D model we can add a virtual safety margin. This leads to extend the resection to the adjacent segment if the intersegmental plan seems compromised. At completion of the segmentectomy, the staple line is examined by frozen section. We know a negative safety margin is not an absolute guarantee against the risk of local recurrence as clusters of malignant cells may be ignored during the intraoperative examination, but it represents nevertheless an additional security.

\section{Extension and conversion}

Analysis of our results showed that the conversion rate to thoracotomy $(6 \%)$ is slightly higher than our overall conversion rate for other thoracoscopic segmentectomies that was previously reported to be $3.1 \%$ (19). Recently, Igai et al. found that their conversion rate for so-called "uncommon segmentectomies" was 5.4\% (25). Our extension rate raises more questions. A total of 17 patients initially planned for CBS had a larger resection (27\%), either to the adjacent segment or to the entire basal segmentectomy or even lower lobectomy. One of the reasons is the need for obtaining safe margins in patients operated on for malignancy, which resulted in an extended resection in 3 patients of our series. This point is crucial to prevent local recurrence, as recently highlighted (26). Two other explanations for extension are more specific to CBS: difficulties in stapling the ISP ( 3 patients) and localization and finding of the target nodule (5 patients). The fact that we could not find the nodule in the firstly resected parenchyma may surprise surgeons unfamiliar with these procedures. In fact, the lack of digital palpation and the pyramidal shape of the basal segments may lead to insufficient resection when the lung is collapsed by selective ventilation. We must point out that for the 5 cases of target nodule not found on the specimen, ICG was not available, suggesting inadequate stapling of the ISP based on doubtful ISP delineation using ventilation technique. The usefulness of IRI to achieve proper oncological margins has been demonstrated by Mehta et al. (26).

This study reports some limitations that should be cited. Although it represents a relatively large case series in the 
literature, our study describes a retrospective, single-center, heterogeneous patient's population during a long-lasting analyzed period in which improvements in the surgical technique throughout the learning curve, and the adoptions of several technologies may have altered the outcomes.

In conclusion, partial segmentectomies of the basal pyramid are justified in a number of indications. Technical complexity may be reduced by the use of preoperative $3 \mathrm{D}$ modelling, mapping and ISP marking. Despite those aids, these interventions remain demanding. However, in our experience, morbidity is low and post-operative results are satisfactory. In patients with NSCLC, intraoperative analysis of safety margins and intersegmental lymph nodes is an oncological prerequisite and extension should be performed every time margins are insufficient or when positive intersegmental lymph node are intraoperatively confirmed (27).

\section{Acknowledgments}

Funding: None.

\section{Footnote}

Reporting Checklist: The authors have completed the STROBE reporting checklist. Available at https://dx.doi. org/10.21037/jtd-20-3521

Data Sharing Statement: Available at https://dx.doi. org/10.21037/jtd-20-3521

Conflicts of Interest: All authors have completed the ICMJE uniform disclosure form (available at https://dx.doi. org/10.21037/jtd-20-3521). ASG reports personal fees from Medtronic, personal fees from Astra Zeneca, outside the submitted work. DG reports personal fees from Medtronic company for presentations in relation with this topic, and he is consultant for an instrument manufacturer (DelacroixChevalier). In addition, DG serves as an unpaid editorial board member of Fournal of Thoracic Disease from Apr 2020 to Mar 2022. The other authors have no conflicts of interest to declare.

Ethical Statement: The authors are accountable for all aspects of the work in ensuring that questions related to the accuracy or integrity of any part of the work are appropriately investigated and resolved. The study was conducted in accordance with the Declaration of Helsinki (as revised in 2013). The study was approved by the Ethical Committee for Clinical Research of the French Society for Thoracic and Cardiovascular Surgery (CERC-SFCTCV2020-07-03---13-SEAG) and individual consent for this retrospective analysis was waived.

Open Access Statement: This is an Open Access article distributed in accordance with the Creative Commons Attribution-NonCommercial-NoDerivs 4.0 International License (CC BY-NC-ND 4.0), which permits the noncommercial replication and distribution of the article with the strict proviso that no changes or edits are made and the original work is properly cited (including links to both the formal publication through the relevant DOI and the license). See: https://creativecommons.org/licenses/by-nc-nd/4.0/.

\section{References}

1. Cao C, Tian DH, Wang DR, et al. Sublobar resectionscurrent evidence and future challenges. J Thorac Dis 2017;9:4853-5.

2. Macke RA, Schuchert MJ, Odell DD, et al. Parenchymal preserving anatomic resections result in less pulmonary function loss in patients with Stage I non-small cell lung cancer. J Cardiothorac Surg 2015;10:49.

3. Sato M, Murayama T, Nakajima J. Thoracoscopic staplerbased "bidirectional" segmentectomy for posterior basal segment (S10) and its variants. J Thorac Dis 2018;10:S1179-86.

4. Nomori H, Okada M. Illustrated anatomical Segmentectomy for Lung Cancer. 1st edition. Tokyo: Springer-Verlag, 2012.

5. Seguin-Givelet A, Grigoroiu M, Brian E, et al. Planning and marking for thoracoscopic anatomical segmentectomies. J Thorac Dis 2018;10:S1187-94.

6. Lutz JA, Seguin-Givelet A, Grigoroiu M, et al. Oncological results of full thoracoscopic major pulmonary resections for clinical Stage I non-small-cell lung cancer. Eur J Cardiothorac Surg 2019;55:263-70.

7. Dindo D, Demartines N, Clavien PA. Classification of surgical complications: a new proposal with evaluation in a cohort of 6336 patients and results of a survey. Ann Surg 2004;240:205-13.

8. Gossot D. Atlas of Endoscopic Major Pulmonary Resections. 2nd edition. Springer International Publishing, 2018.

9. Gossot D. Totally thoracoscopic basilar segmentectomy. Semin Thorac Cardiovasc Surg 2011;23:67-72. 
10. Igai H, Kamiyoshihara M, Kawatani N, et al. Thoracoscopic lateral and posterior basal $(\mathrm{S} 9+10)$ segmentectomy using intersegmental tunnelling. Eur J Cardiothorac Surg 2017;51:790-1.

11. Handa Y, Tsutani Y, Mimae T, et al. Complex segmentectomy in the treatment of stage IA non-small-cell lung cancer. Eur J Cardiothorac Surg 2020;57:114-21.

12. Nomori H, Shiraishi A, Cong Y, et al. Differences in postoperative changes in pulmonary functions following segmentectomy compared with lobectomy. Eur J Cardiothorac Surg 2018;53:640-7.

13. Gossot D, Seguin-Givelet A. Anatomical variations and pitfalls to know during thoracoscopic segmentectomies. J Thorac Dis 2018;10:S1134-44.

14. Sekine Y, Itoh T, Toyoda T, et al. Precise Anatomical Sublobar Resection Using a 3D Medical Image Analyzer and Fluorescence-Guided Surgery With Transbronchial Instillation of Indocyanine Green. Semin Thorac Cardiovasc Surg 2019;31:595-602.

15. Abdelsattar ZM, Blackmon SH. Using novel technology to augment complex video-assisted thoracoscopic single basilar segmentectomy. J Thorac Dis 2018;10:S1168-78.

16. Akiba T, Nakada T, Inagaki T. Three-dimensional pulmonary model using rapid-prototyping in patient with lung cancer requiring segmentectomy. Ann Thorac Cardiovasc Surg 2014;20 Suppl:490-2.

17. Endoh M, Oizumi H, Kato H, et al. Posterior approach to thoracoscopic pulmonary segmentectomy of the dorsal basal segment: A single-institute retrospective review. J Thorac Cardiovasc Surg 2017;154:1432-9.

18. Sato M, Yamada T, Menju T, et al. Virtual-assisted lung mapping: outcome of 100 consecutive cases in a single institute. Eur J Cardiothorac Surg 2015;47:e131-9.

19. Gossot D, Lutz JA, Grigoroiu M, et al. Unplanned Procedures During Thoracoscopic Segmentectomies. Ann
Thorac Surg 2017;104:1710-7.

20. Whitson BA, Groth SS, Andrade RS, et al. Survival after lobectomy versus segmentectomy for stage I non-small cell lung cancer: a population-based analysis. Ann Thorac Surg 2011;92:1943-50.

21. Fang Z, He J, Fang W, et al. Long-term Outcomes of Thoracoscopic Anatomic Resections and Systematic Lymphadenectomy for Elderly High-risk Patients with Stage IB Non-small-cell Lung Cancer. Heart Lung Circ 2016;25:392-7.

22. Huang Q, Wang R, Gu C, et al. Appropriate lymphadenectomy significantly reduced recurrence after segmentectomy for patients with non-small cell lung cancer. J Thorac Dis 2018;10:1919-26.

23. Schuchert MJ, Pettiford BL, Keeley S, et al. Anatomic segmentectomy in the treatment of stage I non-small cell lung cancer. Ann Thorac Surg 2007;84:926-32; discussion 932-3.

24. Iwano S. Planning video-assisted thoracic surgery segmentectomy using three dimensional computed tomography angiography and bronchography with a virtual safety margin. J Vis Surg 2017;3:82.

25. Igai H, Kamiyoshihara M, Yoshikawa R, et al. The safety and feasibility of thoracoscopic uncommon pulmonary segmentectomy. J Thorac Dis 2019;11:2788-94.

26. Mehta M, Patel YS, Yasufuku K, et al. Near-infrared mapping with indocyanine green is associated with an increase in oncological margin length in minimally invasive segmentectomy. J Thorac Cardiovasc Surg 2019;157:2029-35.

27. Mimae T, Okada M. Are segmentectomy and lobectomy comparable in terms of curative intent for early stage non-small cell lung cancer? Gen Thorac Cardiovasc Surg 2020;68:703-6.
Cite this article as: Gossot D, Mariolo AV, Grigoroiu M, Bardet J, Boddaert G, Brian E, Seguin-Givelet A. Thoracoscopic complex basilar segmentectomies: an analysis of 63 procedures. J Thorac Dis 2021;13(7):4378-4387. doi: $10.21037 /$ jtd-20-3521 